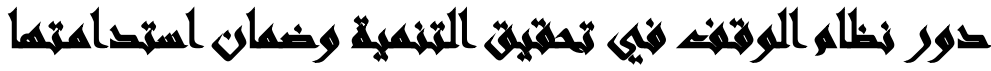

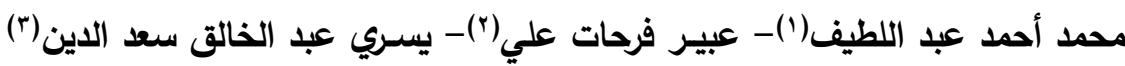

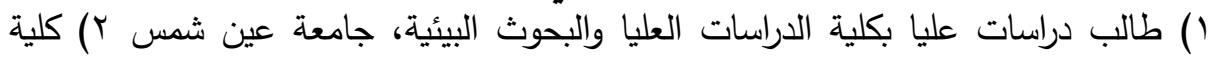
التجارة، جامعة عين شمس ب) كلية أصول الدين (طنطا)، جامعة الأزهر البعرية

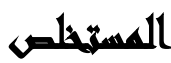

يحظى مفهوم التتمية منذ منتصف القرن العشرين باهتمام واسع، باعتباره أمل الدول

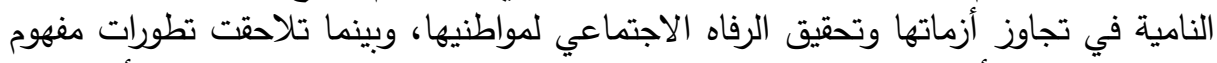

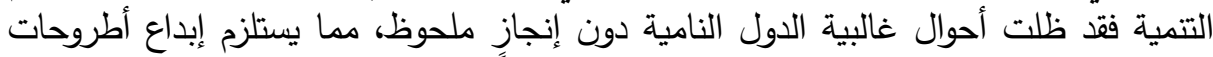

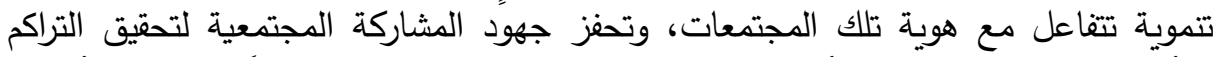

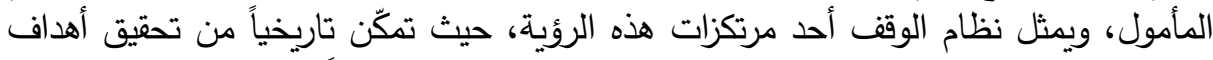

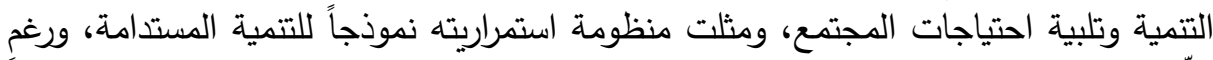

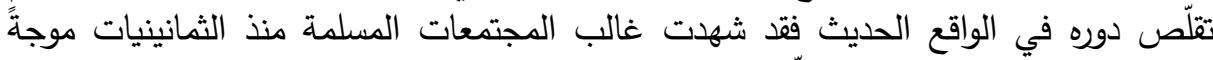

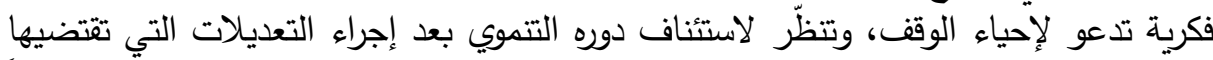

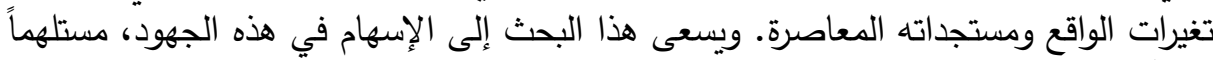

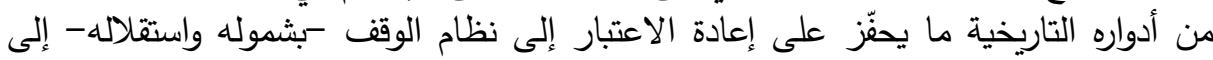

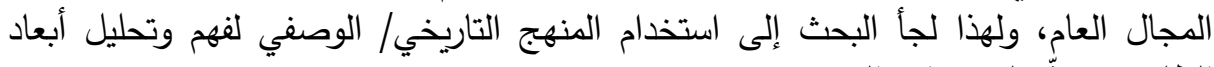

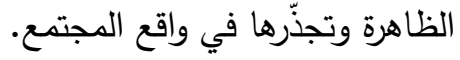

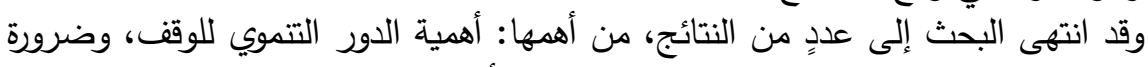

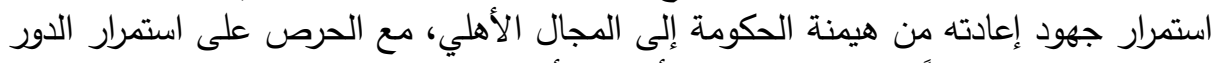

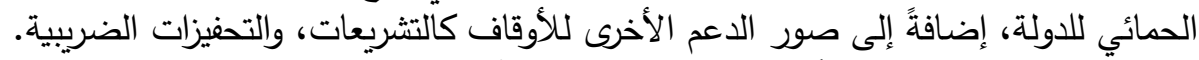

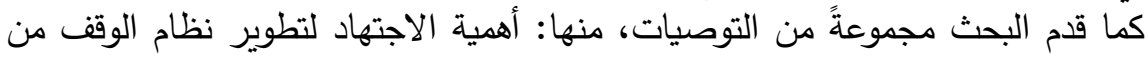

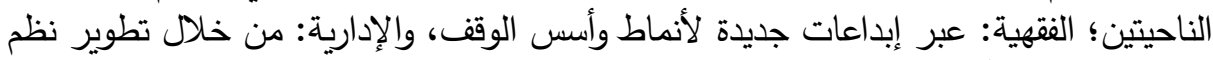

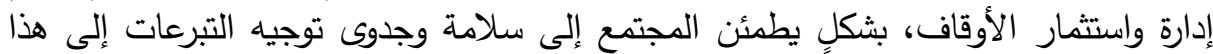

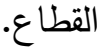
الكلمات المفتاحية: نظام الوقف، الأوقاف في مصر ، إنجازات الوقف، إحياء الوقف، مشكلات

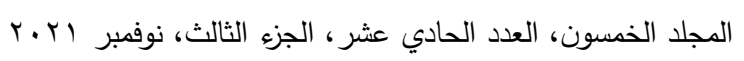

الترقيم الدولي

$$
\text { الترقيم الدولي الموحد الإكتروني 3178-2636 }
$$




\section{$x$}

عرفت البشرية أنماطاً من المعاملات المالية الطوعية التي لا تخرج في طبيعتها عن

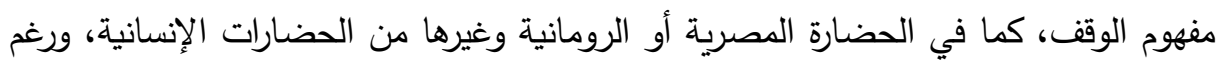

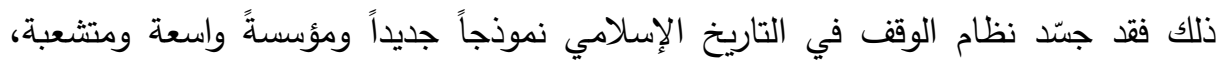

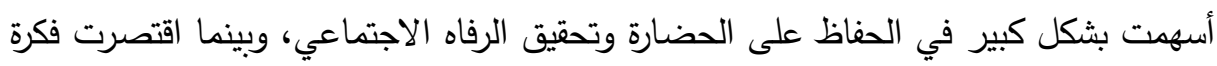

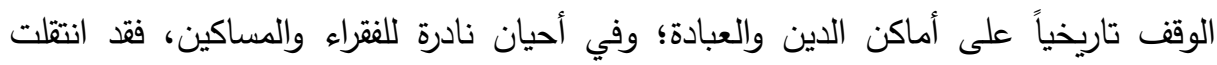
الحضارة الإسلامية بالوقف إلى أرقى مستويات التتمية الثاملة، فكان للوقن إنجازاته

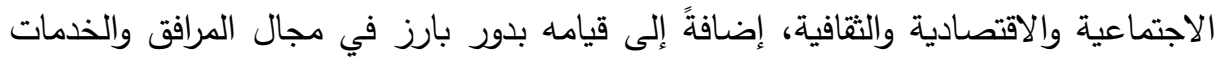

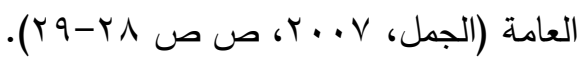

وتتأسس منظومة الوقف في الفكر الإسلامي على مبدأ المسئولية الاجتماعية للمال،

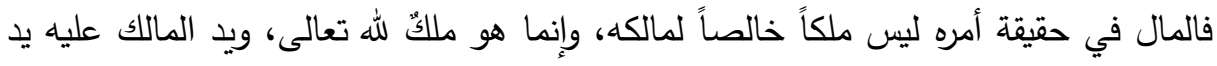

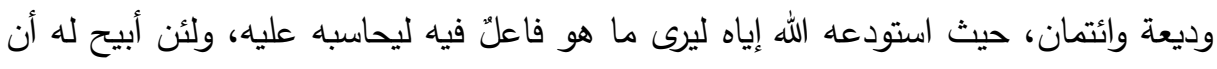
يستمتع بطيبات الرزق فإنّ ذلك مشروطُ بالاقتصاد وعدم التبذير ، ولا نجاة للإنسان إلا بتحرّي

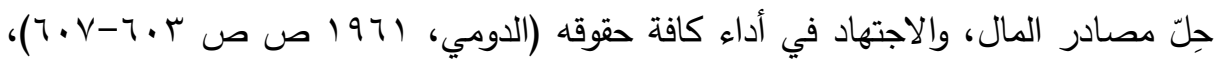
ولهذا تتافس رواد تلك المجتمعات في أداء هذه التكاليف التي أطلق عليه حديثاً مفهوم "المسئولية الاجتماعية" Social Responsibility، فجسدت إنجازاتهم أسمى نماذج المسئولية التي تجمع بين الأبعاد الإيمانية والحضارية. وسعياً إلى إبداع رؤية تتموية فقد أسهمت الدراسات الوقفية الحئه الحديثة في إعادة الاعتبار

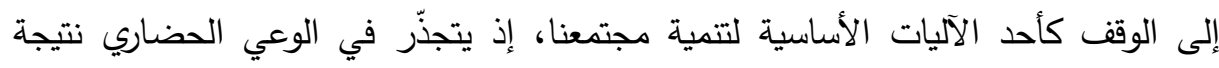

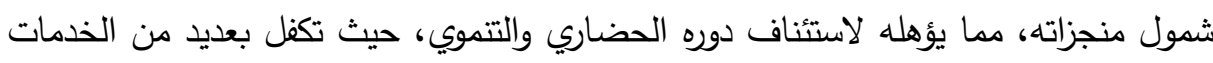

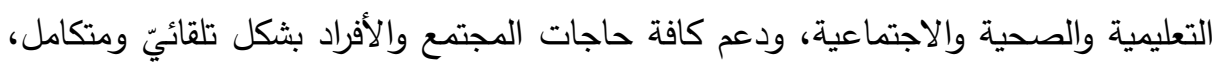
مما خفّف عن كاهل الدولة عديداً من المسئوليات الاجتماعية، حيث كانت فكرة بقاء أمواله 266

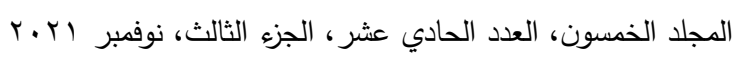

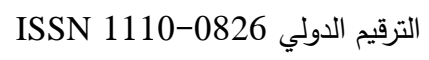

$$
\text { الترقيم الدولي الموحد الإكتروني 3178-2636 }
$$


وإنفاق أرباحها نموذجاً إبداعياً حقّق لتلك الحضارة مبدأ الاستدامة واستمرارية التمويل الذي

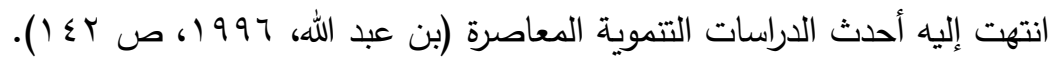

\section{And ILan}

يعاني المجتمع المصري -كغالب الدول النامية- من إخفاق جهود التتمية، حيث احتلت

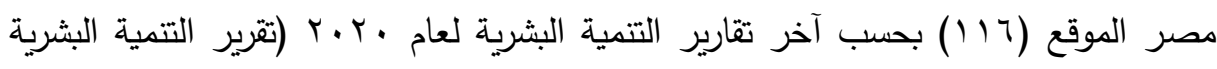

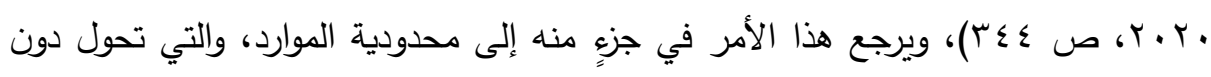

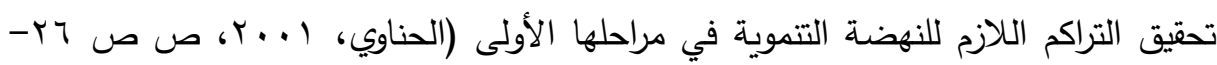

ونظراً لتعدد الكبوات في مسار التتمية منذ منتصف القرن العشرين؛ فقد طرح عددٌ من

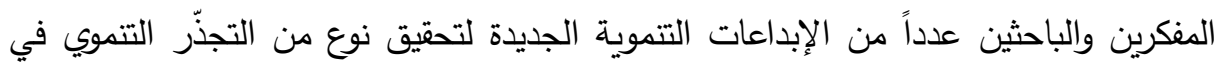
وعي المجتمع، ويمثل نظام الوقف أحد أهمّ هذه النماذج، باعتباره أحد الدعائم الأساسية

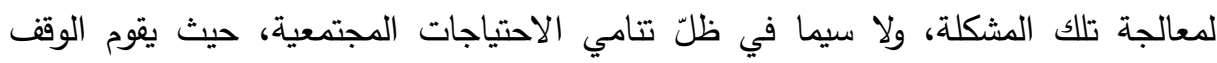

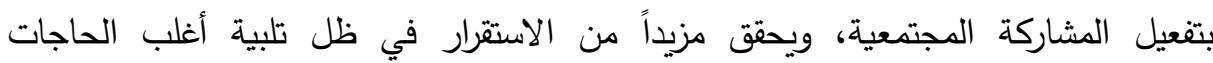

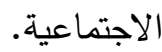

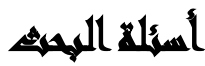

يسعى هذا البحث إلى الإجابة على سؤال محوري: إلى أي مدى يصلح نظام الوقف لدعم

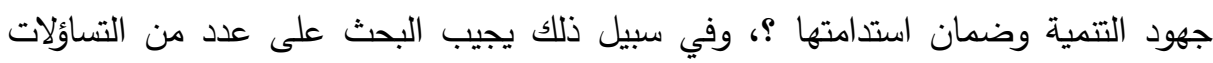
الفرعية، ومن أهمّ هذه التساؤلات :

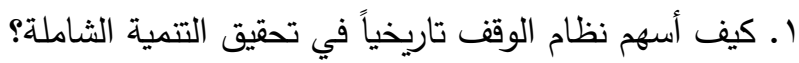

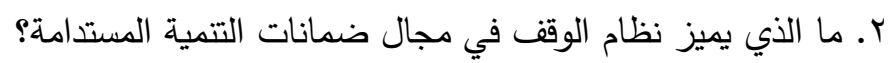
r. إلى أي مدى يمكن لنظام الوقف أداء دور تتموي معاصر ، وما شروط ذلك؟ فئ

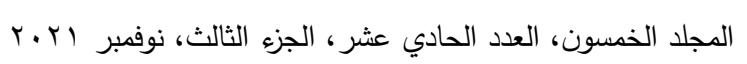

الترقيم الدولي 0826- ISSN 1110

$$
\text { الترقيم الدولي الموحد الإكتروني 3178-2636 }
$$




\section{أهفالهي المهند}

1-بيان معنى الوقف وركائزه الشرعية، وسمات الاستمرار والاستدامة التي يتميز بها. r-إبراز الدور التاريخي لنظام الوقف في تحقيق التتمية المجتمعية وضمان استدامتها. ب-استعراض أحوال نظام الوقف في الواقع الدعاصر ، وبيان أهمّ مشكلاته. ع-تحديد متطلبات إحياء نظام الوقف للإسهام بدور فاعل في جهود التنمية.

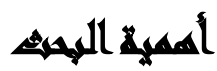

الأهمية النظرية: يمثل هذا البحث أحد الدراسات الوقفية التي تدعم الجهود الفكرية الراهنة

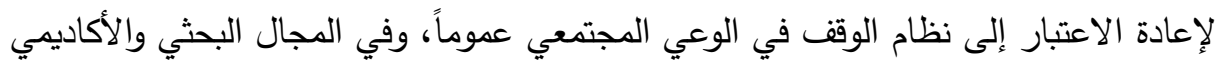
خصوصا. الأهمية التطبيقية: يسعى هذا البحث إلى ترشيد جهود إحياء الوقف، بتحديد الخطوات العملية اللازمة لتطوير نظام الوقف من جانب، وبيان مسئولية الأطراف المختلفة -الدولة، والفقهاء،

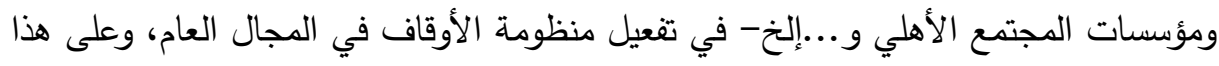
الأساس يمكن أن تستفيد منه عدد من الجهات، من أهمها: المجالس التشريعية، مجلس

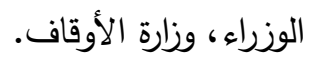

\section{همسلحماهي الهمبه}

الوقف: هو نظام إسلاميّ للإحسان الواسع، يقوم المتبرّع بمقتضاه بـ (تحبيسُ أصلٍ، مع تسبيل

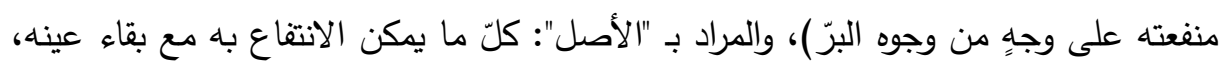

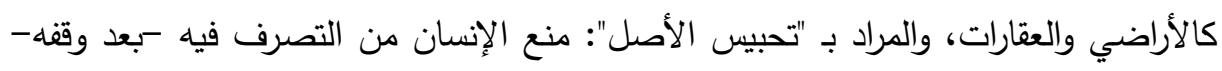

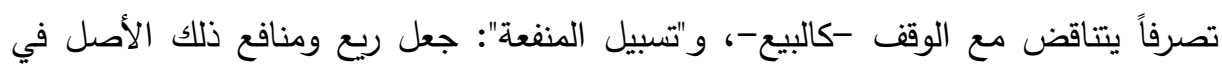

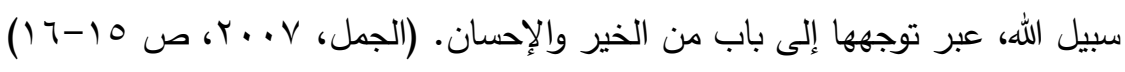

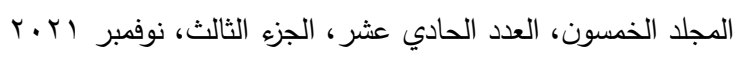

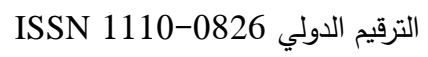

$$
\text { الترقيم الدولي الموحد الإكتروني 3178-2636 }
$$


التنمية: يُنظَر إلىى التتمية كانتقال من حالٍ إلى حال أفضل؛ خلال فترة زمنية معينة يحدّدها

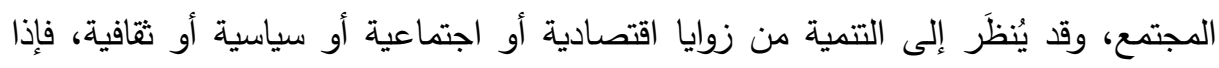

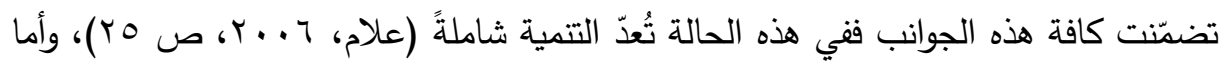
التتمية المستدامة: فهي "التتمية التي تفي باحتياجات الأجيال الحاضرة، دون المساومة على لفاه

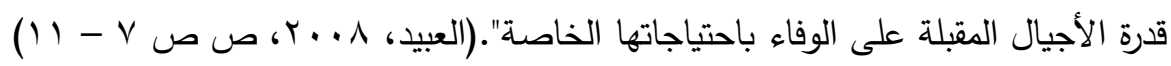

\section{السوراساهت الساريهن}

تزخر المكتبة العربية بعدٍٍ كبير من الدراسات الوقفية، سواء كان ذلك على المستوى

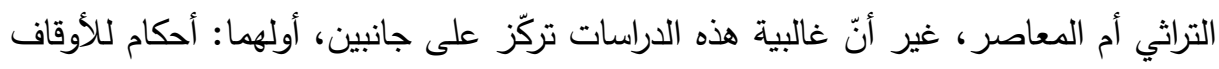

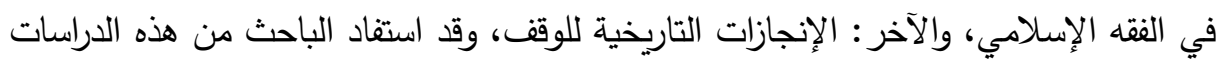
لتحليل الظاهرة الوقفية، وتحديد مشكلاتها في العصر الحديث، وآفاق تطويرها، ومن أهم

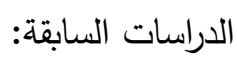
حسن عبد الله الأمين (؟9 9 1): خصّص الباحث الجزء الأول من الدراسة كإطار نظري

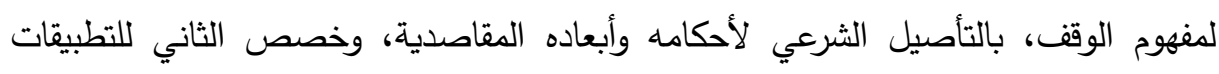

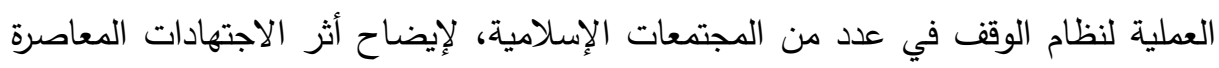
في إحياء معالم الوقف، وتوسيع نظرة المهتمين بإحياء الأوقاف في الواقع الحديث.

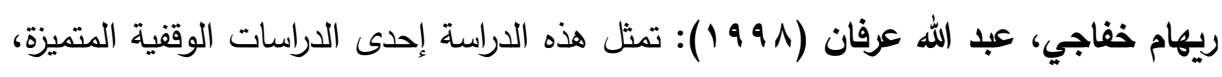

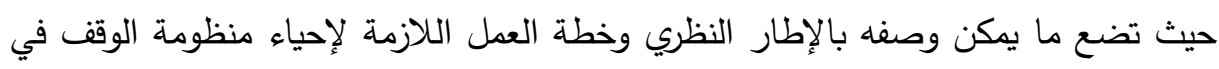

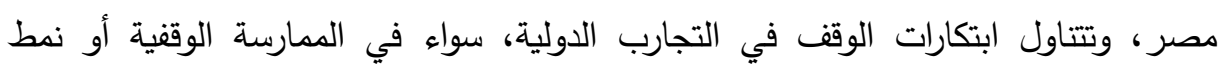

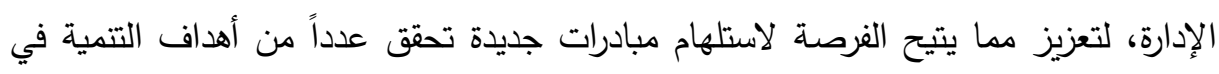

الترقيم الدولي 0826- ISSN 1110 الترقيم الدولي الموحد الإكتروني 3178-2636 
محمد سعد أبو الفتوح الفقي (Y Y Y): استعرضت الدراسة إنجازات نظام الوقف -ولا سيما

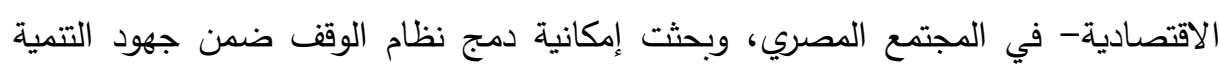

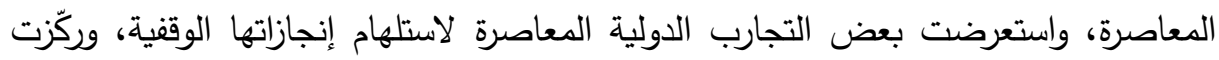

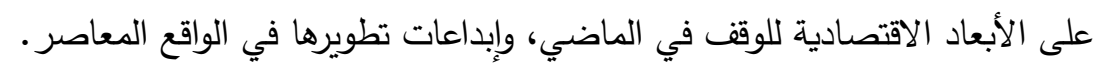
Adam Abdullah and Buerhan Saiti (2016): A Re-Examination of Musharakah Bonds and Waqf Development: The Case of Singapore. Intellectual Discourse, Special Issue.

تبحث هذه الدراسة مشروعية وآثار نظام التمويل العقاري اعتماداً على نظام المشاركات

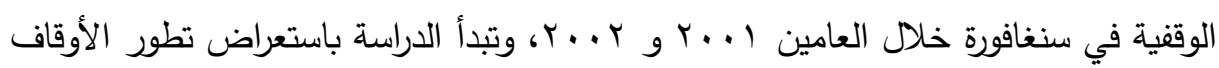
الإسلامية في سنغافورة، وتميز بين مفهوم الوقف وبين الإجارة والشراكة، ثم تعرض كيف تم

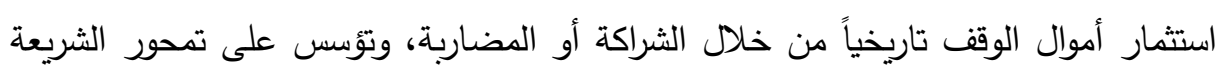

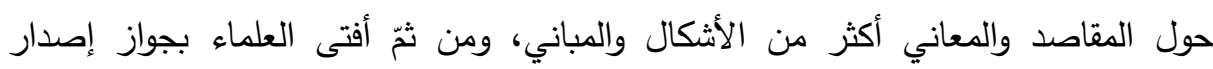

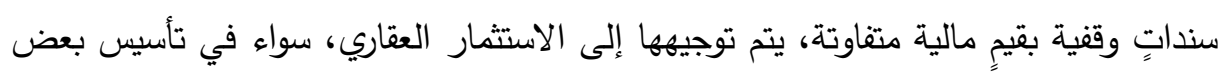

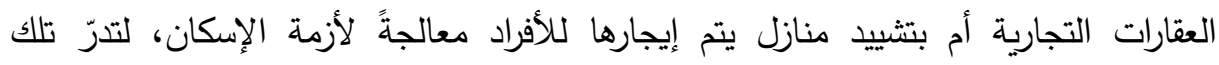

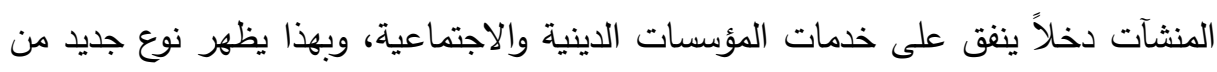
المبادرات الوقفية المستحدثة، والتي تحقق مقاصد الثريعة من جانب، وتلبي احتياجات المجتمع دون عنتٍ من جانبٍ آخر •

\section{الإلطار النظطيه}

تمثل الأوقاف مؤسسةً وطنية كبرى، يثارك فيها كما ينتفع بخدماتها جميع المواطنين،

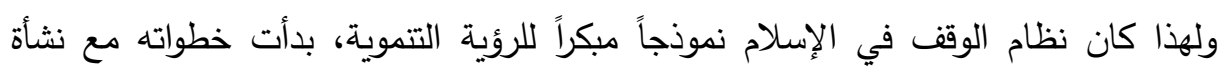

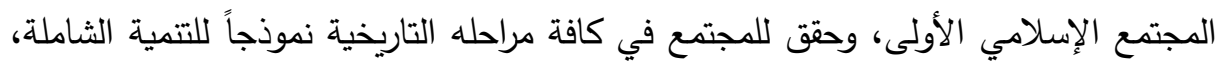
وقام بكافة الوظائف الخدمية ولا سيما في اللحظات التاريخية الحرجة، ولا تزال المؤسسات 270

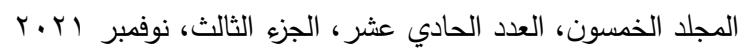

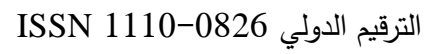

$$
\begin{aligned}
& \text { الترقيم الدولي الموحد الإكتروني 3178-2636-26 }
\end{aligned}
$$


الوقفية باقيةً إلى اليوم منذ قرون طويلة، ومستمرةً في العطاء في مجالات كثيرة، فقد رافق

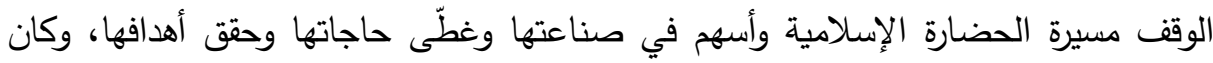

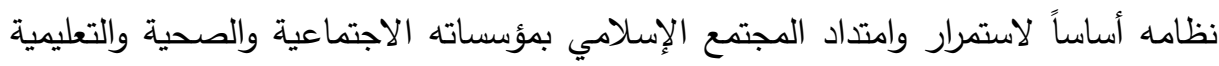

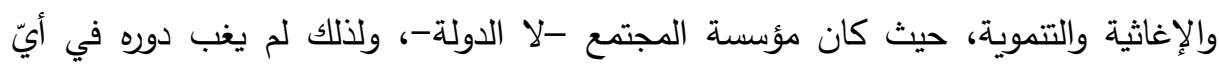

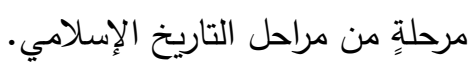
وإذ يمثل بناء الإنسان الصالح وتهذيب أخلاقه وسلوكه أحد أهمّ مقاصد الإسلام، فقد الإدان كانت بداية الأوقاف بالمسجد، باعتباره المدرسة المفتوحة على الدوام لهذا الغرض، فئن فكان

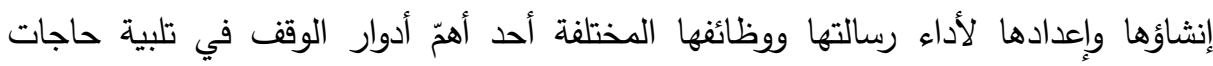
المجتمع الدينية والروحية، فلم تكن المساجد في التاريخ الإسلامي مجرد أماكن لإقامة الصلاة

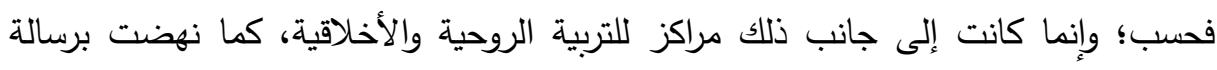
التثقيف ونشر الوعي الديني والعلوم المختلفة، وظلت المساجد تؤدي هذا الدور بكفاءة واقتدار

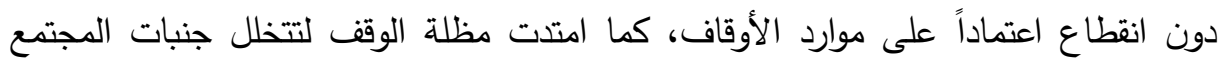
وتلبي احتياجاته، فكان الوقف ركيزةً أساسية للنهضة العلمية والثقافية والطبية، إضافةً إلى الى الثلى عديد من الخدمات والمرافق التي أسهمت في تتمية المجتمع وتحقيق الرفاه الاجتماعي لأفراده،

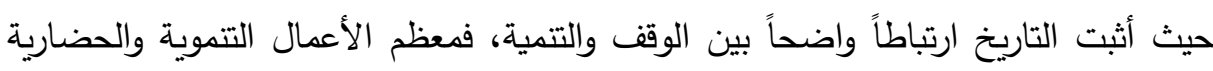

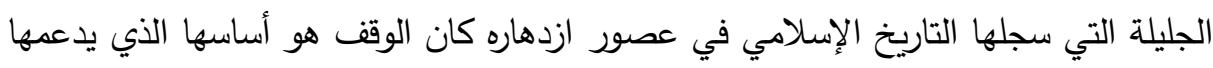

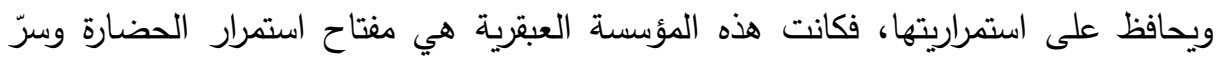

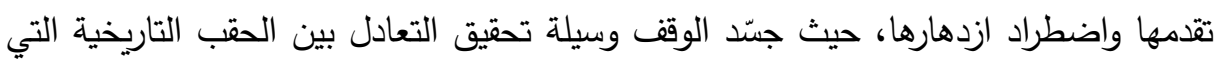

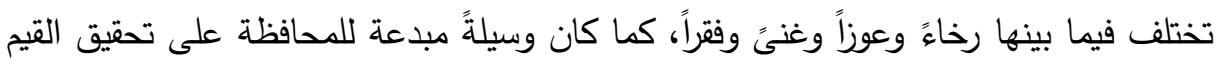
حين تجليها، واستمرار فعاليتها عندما تختلف الظروف التي ظهرت وفهاء هذه القيم في ظلها.

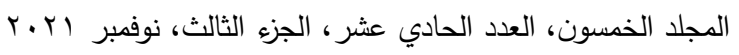

$$
\begin{aligned}
& \text { ISSN 1110-0826 الترقيم الدولي الدوني } \\
& \text { الترقيم الدولي الموحد الإكتروني 3178-2636 }
\end{aligned}
$$




\section{الإجباعايت المنهجية}

نوع البحث: يعد هذا البحث أحد البحوث الوصفية التطورية التي تُعنى بدراسة ووصف الواقع

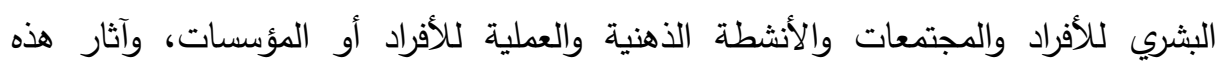

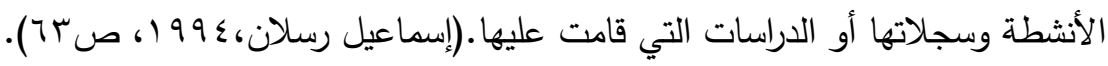

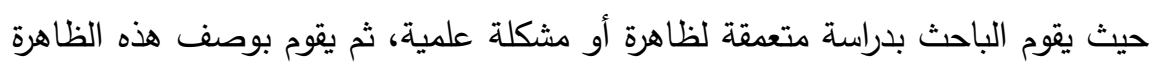
بطريقة علمية، مما يتيح له القدرة على تقديم بعض التقسيرات العلمية للظاهرة من خلال

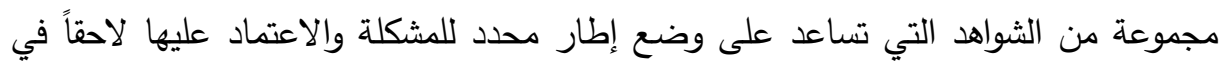
التعامل مع الظاهرة، كما يهتم هذا المنهج بمعرفة التطور الذي تثهده الظاهرة ومدى تأثير مرور الزمن عليها. منهج البحث: نظراً لطبيعة البحث وموضوعه، فقد اعتمد الباحث أولاً على المنهج التاريخي/ الوصفي، لدراسة ظاهرة الوقف في المجتمع المصري خلال مراحله المختلفة، لتوضيح وتحليل

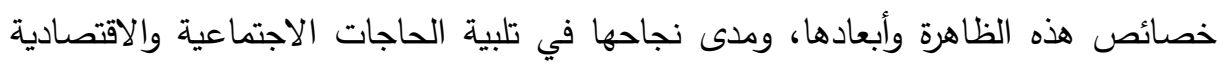

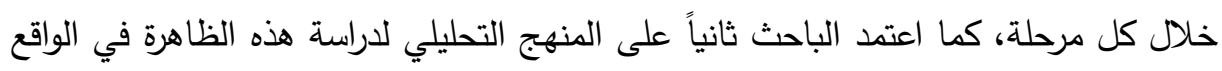

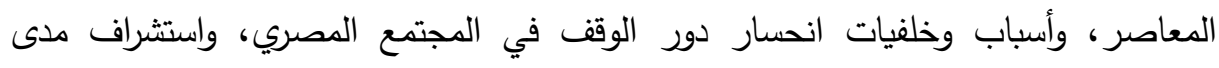

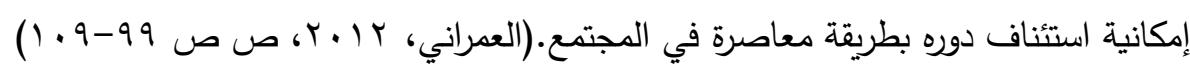
إجراءات البحث: نظراً للطبيعة التاريخية للظاهرة محل البحث؛ فقد اعتمد الباحث في تحصيل المعلومات والبيانات المتعلقة بالظاهرة على المراجع العلمية التي تتاولت ظاهرة

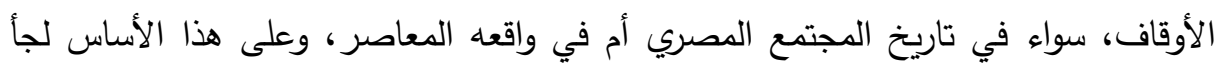

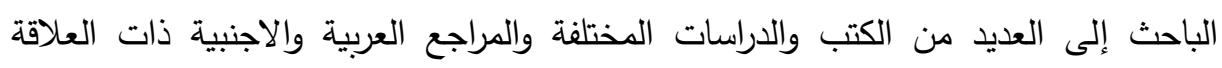
والدوريات والمقالات والأبحاث والمطالعة في مواقع الانترنت، وذلك لاستعراض كيفية إسهام

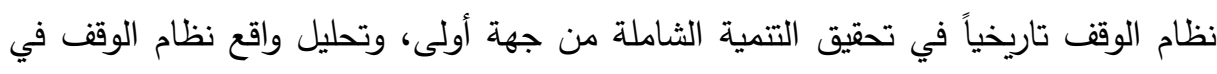

$$
\begin{aligned}
& \text { المجلد الخمسون، العدد الحادي عشر ، الجزء الثالث، نوفمبر اY.r }
\end{aligned}
$$

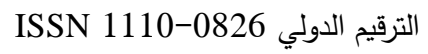

$$
\begin{aligned}
& \text { الترقيم الدولي الموحد الإكتروني 3178-2636 }
\end{aligned}
$$


المجتمع المصري المعاصر من جهة ثانية، وبحث إمكانية تطوير نظام الوقف ليتمكن من أداء دور تتموي معاصر من جهة ثالثة. حدود البحث: نظراً لاتساع وتثعّب ظاهرة الوقف فقد اقتصر البحث على الحدود التالية: الحدود المكانية: اقتصر البحث على المجتمع المصري. الحدود الزمانية: لجأ البحث إلى الاستقراء التاريخي للمجتمع المصري خلال مراحله المختلفة،

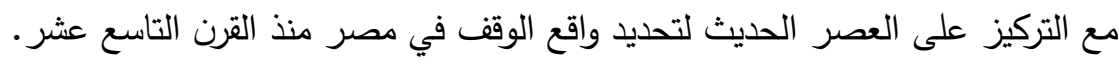

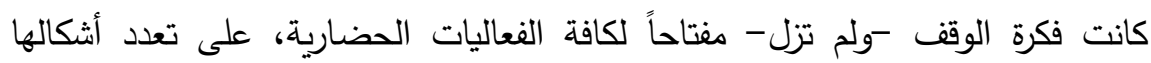
واختلاف أهدافها، إذ تعاملت مع الأساس الاقتصادي الذي يتصف بالندرة والتقلب والتفاوت في ترفي

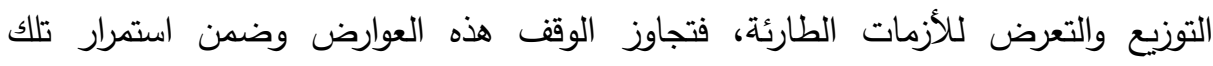

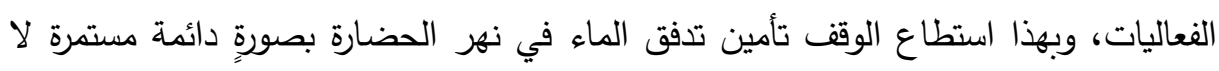

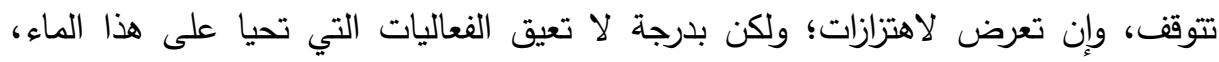

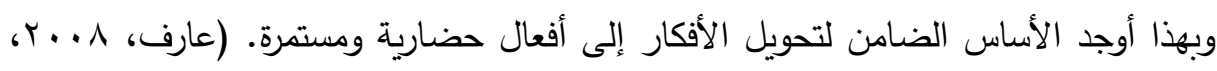

وعلى هذا الأساس يمكن تقييم تاريخ وواقع نظام الوقف في مصر عبر النقاط التالية:

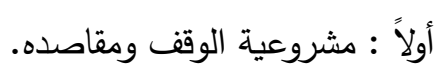

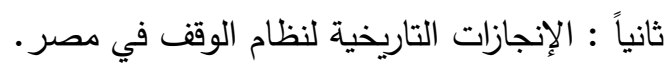
ثالثاً: مشكلات نظام الوقف في مصر • رالِّات

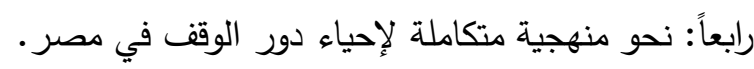

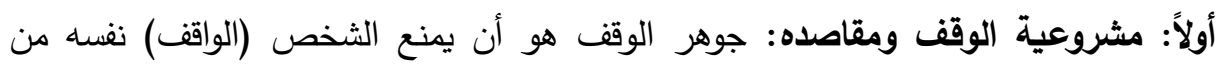

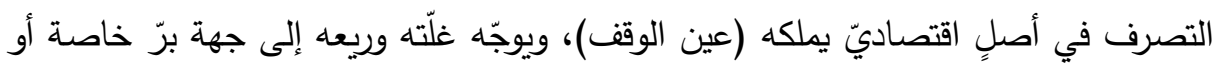
عامة (جهة الوقف)، وبهذا يختلف الوقف عن غيره من التبرعات، فإذا تبرع أحدهم بعقار ، فإنّ التّا للمستفيد من التبرع أن يتصرف في العقار بكافة صور التصرف كبما فيها التصرفات الناقلة

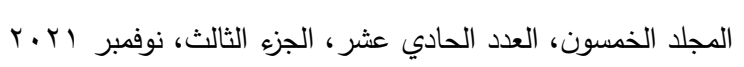

الترقيم الدولي 0826- ISSN 1110

$$
\text { الترقيم الدولي الموحد الإكتروني 3178-2636 }
$$


للملكية كالبيع أو الهبة-، بينما يقصر الوقف انتفاع المستفيدين على ثمرات العقار أو ريعه،

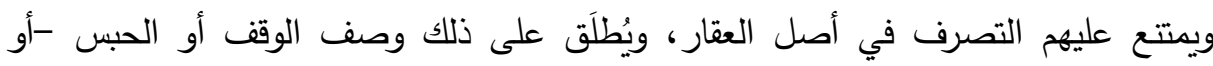

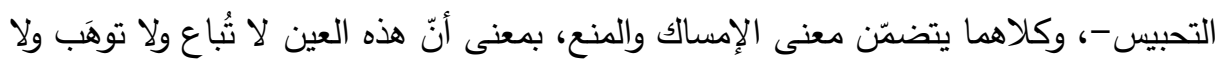

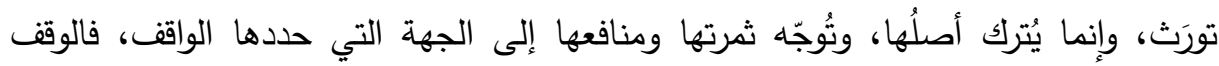

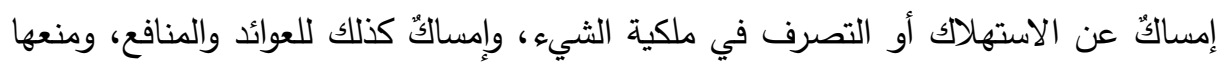

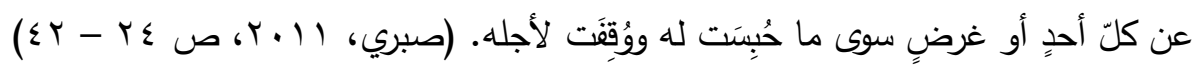
والوقف قربةٌ تعبدية ترتكز مشروعيتها على عدودٍ من الآيات القرآنية والأحاديث النبوية التي تحض على البرّ والإحسان عموماً، أو على الوقف خصوصاً، كالحديث الثهير : " إذَا

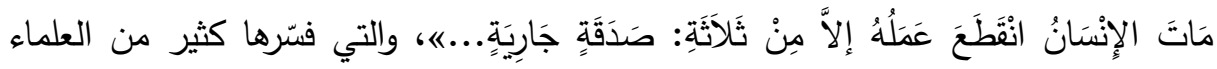

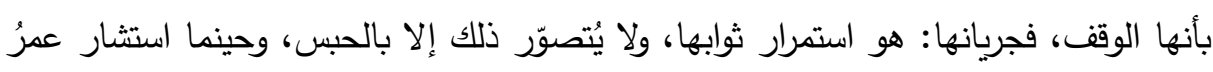

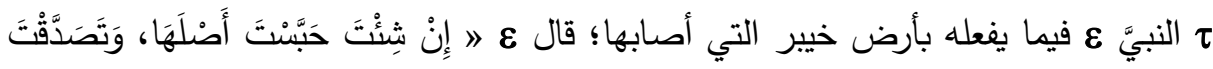

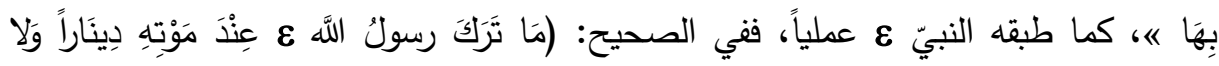

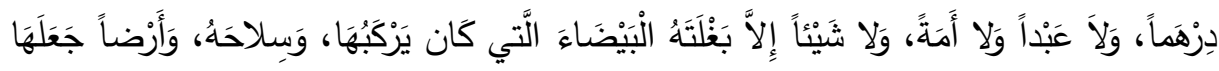

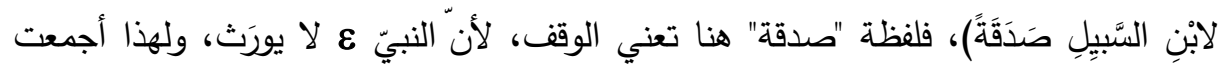
الأمة على مشروعية الوقف -في الجملة-، سواء فيما نقل من أقوال أهل العلم أم فما نفذته لأله الأمة عملياً في كافة البلدان، بوقف المساجد والعقارات والدصاحف والكتب. (الكبيسي،

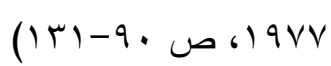
ويرتكز الوقف على التصور الإسلامي للملكية، والوظيفة الاجتماعية للمال، حيث يتميز

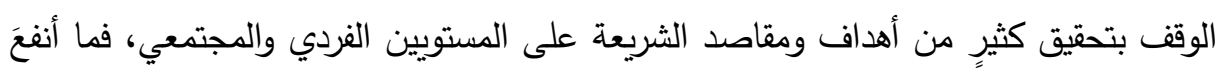

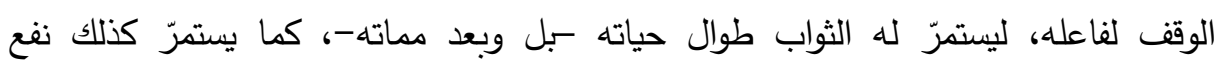
الموقوف عليهح من الفقراء وأبناء السبيل وطلاب العلم وغيرهم-، فالعطاء الآنيّ يبقى محدوداً

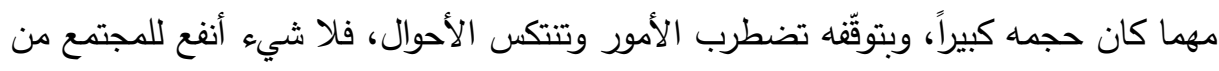

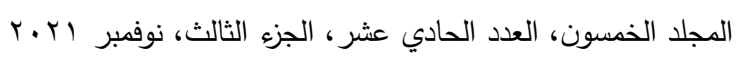

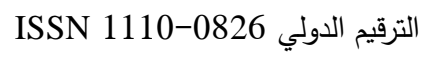

$$
\text { الترقيم الدولي الموحد الإكتروني 3178-2636 }
$$


حبس أصحاب المال لبعض أموالهم، ليبقى الأصل قائماً؛ ويتواصل إدرار الثرة والمنافع على الثى

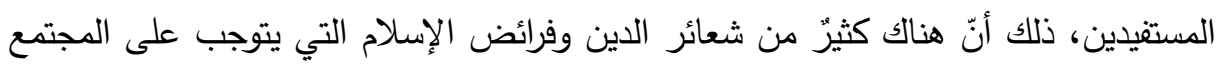

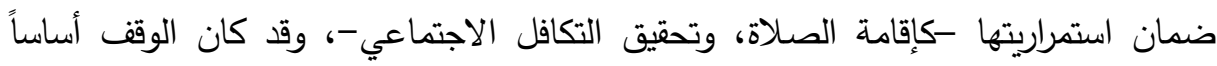

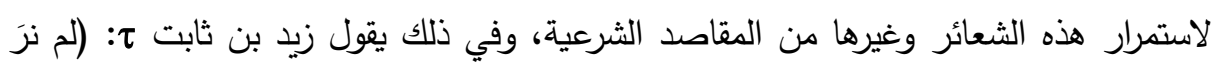

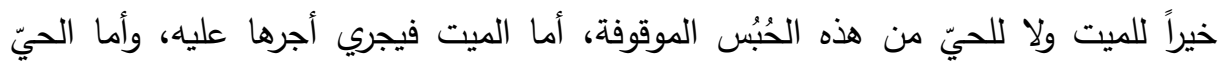

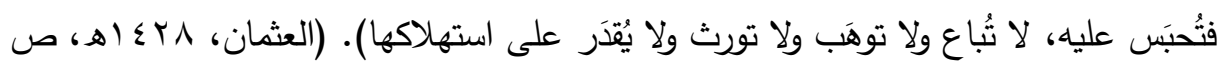

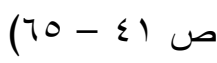

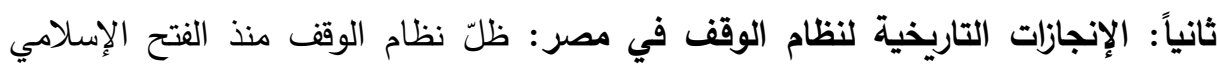

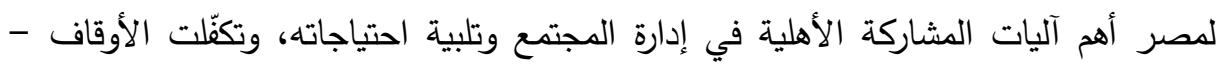

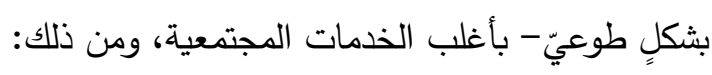

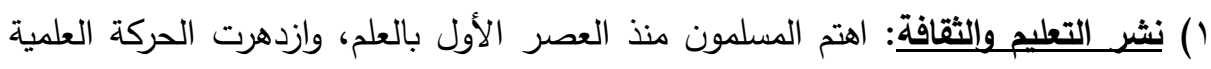

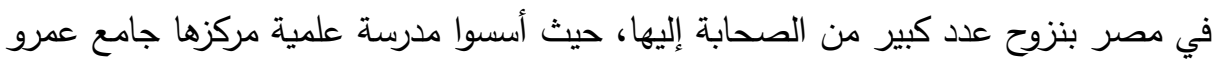

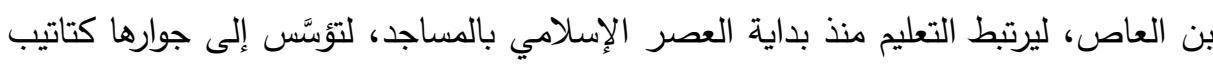

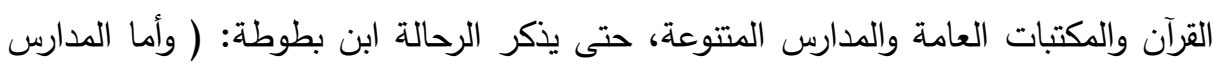

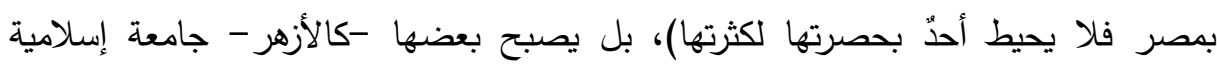

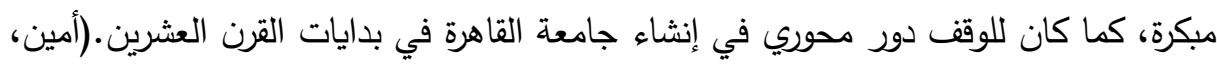

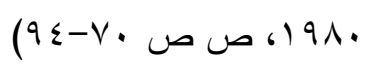
r الرعاية الصحية: ازدهرت الخدمات الطبية الوقفية في مصر طوال تاريخها، وأنثأ

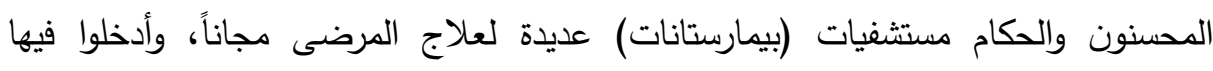

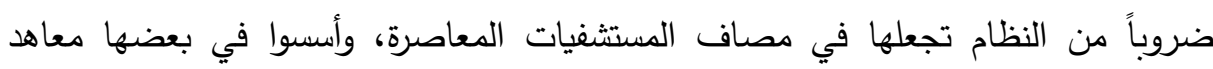

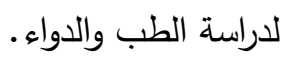

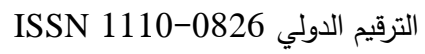
الترقيم الدولي الموحد الإكتروني 3178-2636 لتربي 
r) الخدمات العامة: انتشرت في مدن مصر وقراها أوقاقُ خيرية لتأسيس "أسبلة" الماء العذب والحمّامات العامة، إضافةُ إلى أوقاف مساعدة المحتاجين من الفقراء والأيتام، وإطعام الجائعين وكسوة العارين، و"خانات" أبناء السبيل على طرق المسافرين وداخل المدن، و"مضايف" إكرام الضيوف والوافدين.

وهكذا أبدع نظام الوقف في ظلّ مبادئ ثلاثة ضمنت له الحيوية والفعالية، أولها: احترام شروط الواقفين ووجوب التزامها، والثاني: إسباغ الثخصية الاعتبارية على الأوقاف، والثالث: اختصاص القضاء بالإشراف على نظام الوقف، مما حافظ على استقلالية الأوقاف عن الدولة الألة

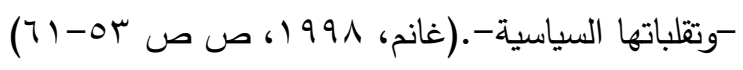

ثالثاً: مشكلات نظام الوقف في مصر: استمر نظام الوقف في مصر منذ الفتح الإسلامي

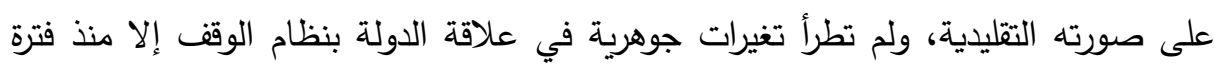
حكم محمد علي، والذي اتجه إلى إحكام قبضة الدولة بشكل مركزيّ على كافة الأنثطة

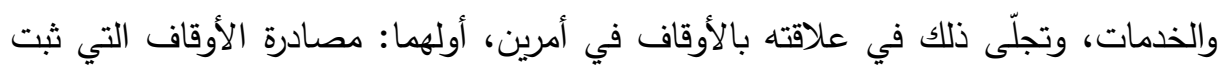

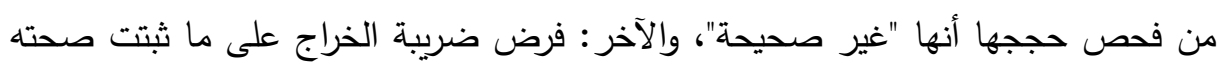

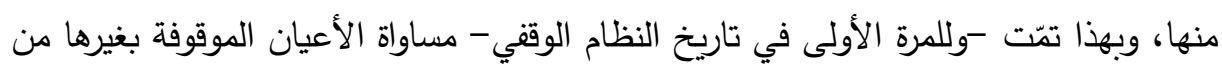
الممتلكات الخاصة في دفع "أموال الميري" للدولة. وبقيام ثورة يوليو تعرض نظام الوقف لضربة قاصمة عبر أربع مراحل، بدأت أولاها

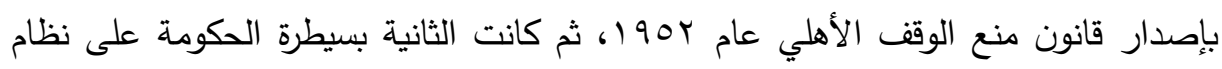

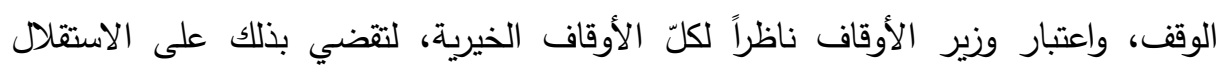

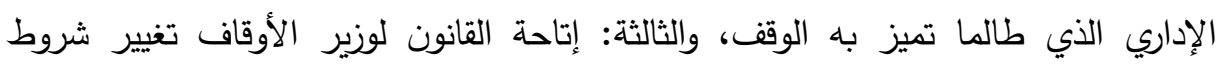
الوقف، وأخيراً: إلزام وزارة الأوقاف بتسليم ما لديها من الأراضي الموقوفة لهيئة الإصلاح

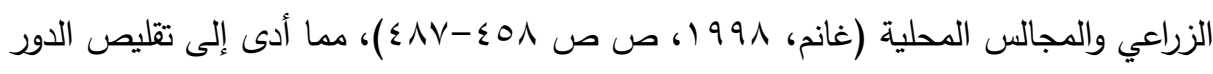


المجتمعي للأوقاف، وعزوف رواد المجتمع تدريجيا عن الإسهام في هذا النظام، كما يتضح

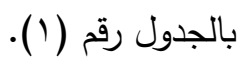

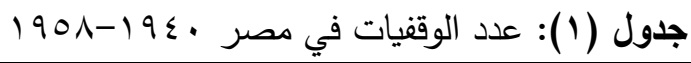

\begin{tabular}{|c|c|c|c|}
\hline $190 \wedge-190 r$ & $190 r-19 \leq 4$ & $19 \leq 7-19 \leq$. & \\
\hline 111 & N9r & TArT & أوقاف جديدة \\
\hline M & $1 \leqslant 9$ & $\varepsilon V Y$ & أوقاف/ سنة \\
\hline
\end{tabular}

المصدر : د. إبراهيم البيومي غانم، مرجع سابق، ص V •. I.

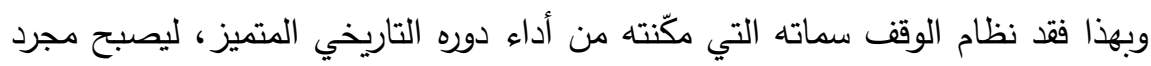
أداة بيد البيروقراطية الحكومية، كما تم استخدام موارده المختلفة لاعم توجهات النظام السياسي، ويظهر ذلك التوجه الواضح من خلال عديد من النماذج، يكتفي البحث بالتركيز على بعضها كما يلي من خلال النقاط التالية:

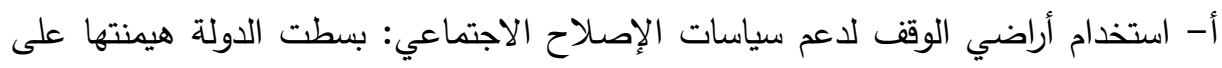

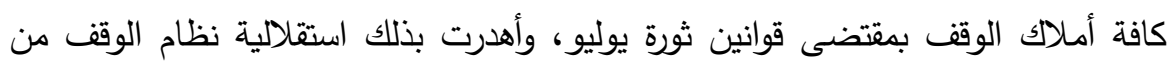

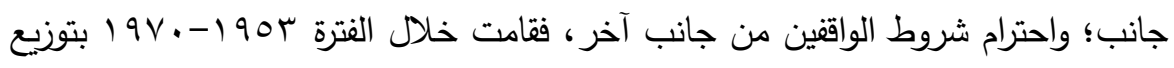

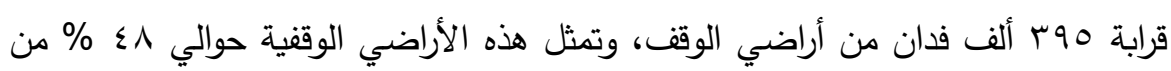

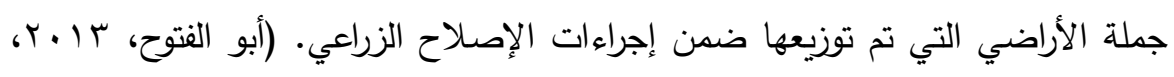

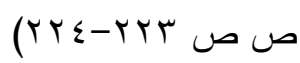
ب- استخدام أموال الوقف وموارده لخدمة أهداف النظام السياسي: استخدمت الدولة موارد

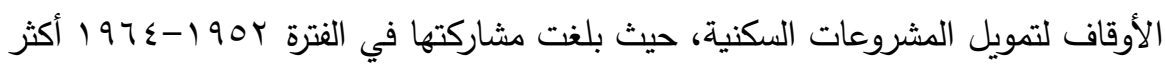

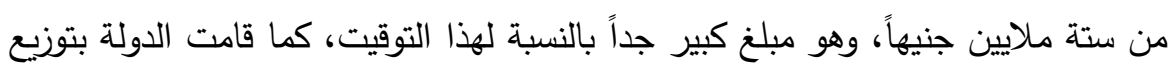

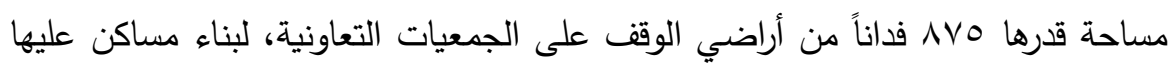

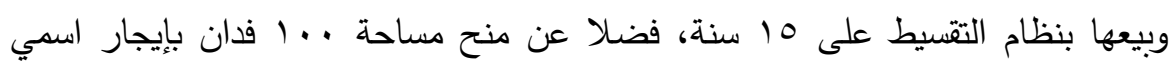

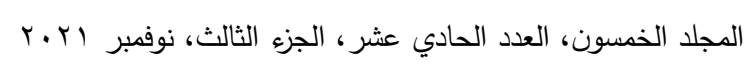

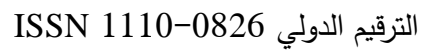

$$
\text { الترقيم الدولي الموحد الإكتروني 3178-2636 }
$$


للأندية الرياضية بالمهندسين، كما تكفلت الأوقاف بكافة تكاليف بناء بعض المنشآت

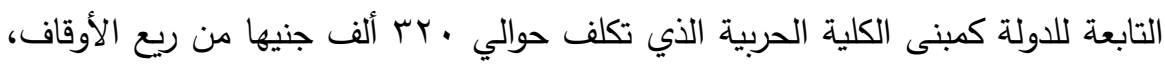

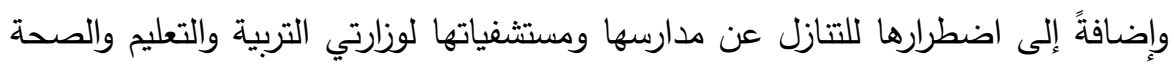

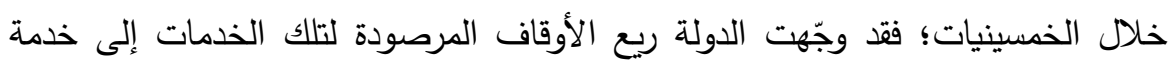
أهداف سياستها الخارجية، ودعم أواصر الصداقة بين مصر والدول الأخرى، دون مراعاة

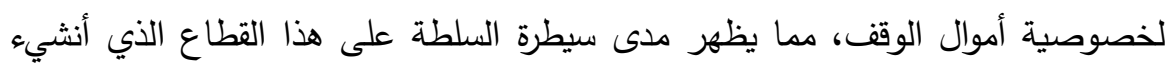

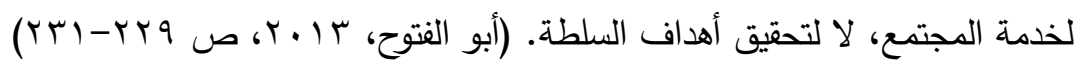

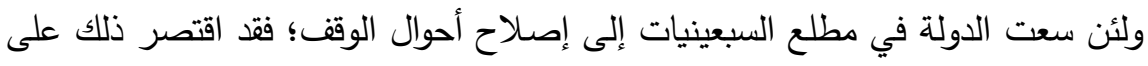

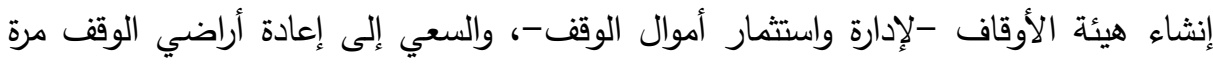
أخرى إلى الجهات الوقفية، لتستمرّ هيمنة الدولة على نظام الوقف بعيداً عن إدارته الأهلية

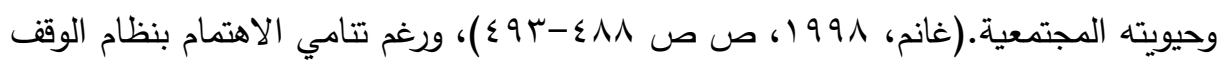

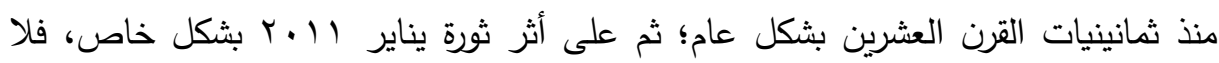
تزال القيود التي تحول دون فعالية نظام الوقف قائمة.

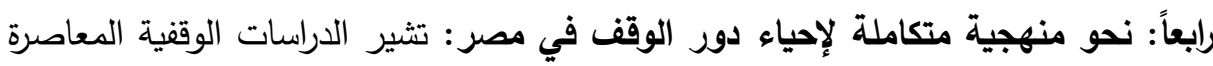

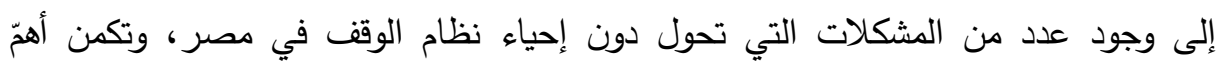

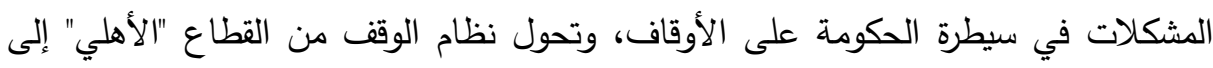

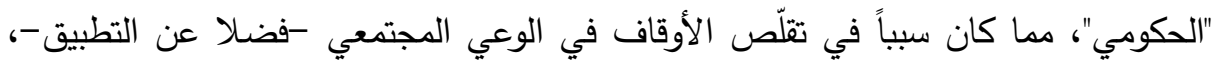
وتتعلّق المشكلة الثانية بوجود قصور داخل نظام الوقف التقليدي، مما يحول بينه وبين مبادرات إيجابية وفاعلة، وبهذا تتحرك مسيرة إحياء الوقف على ثلاثل مسارات متكاملة: () السعي_إلى تحرير نظام الوقف من السبطرة الحكومية: تجدّد الاهتمام الدستوري بنظام

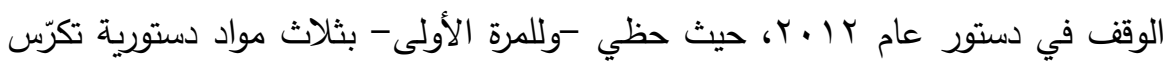

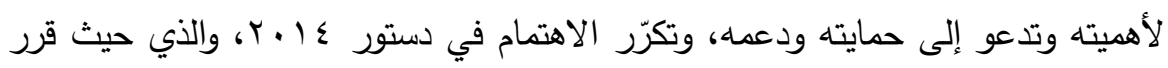

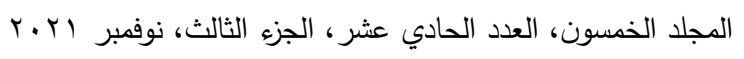

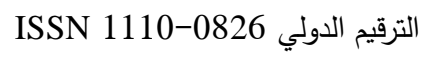
الترقيم الدولي الموحد الإكتروني 3178-2636 
في المادة (•)): "تلتزم الدولة بتشجيع نظام الوقف الخيرى لإقامة ورعاية المؤسسات

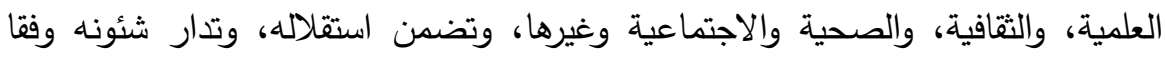

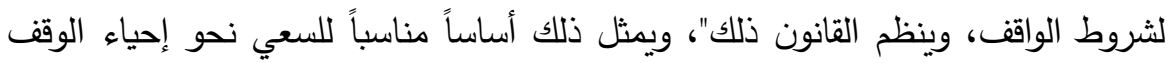
عبر الدعوة إلى إنشاء مجلس أعلى لشئون الأوقاف ذو طابع أهلي -بتمثيل حكومي مناسب-، والذي يضطلع بوضع السياسات العامة والمعايير التيقيمية والإجراءات الرقابية

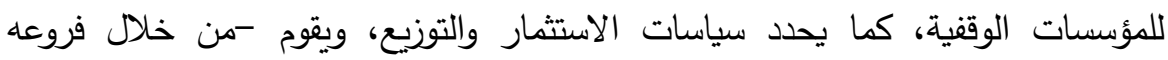

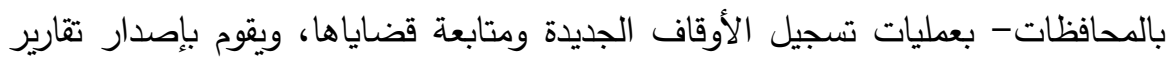
دورية عن أدائه وأداء الإدارات الوقفية المرتبطة به، كما يتولى المجلس سمن خلاتل

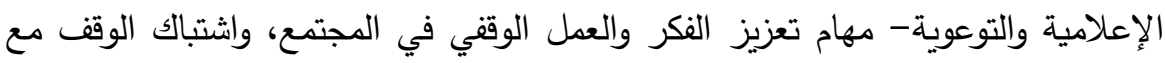
المشكلات والاحتياجات المجتمعية المختلفة، والسعي إلى تعظيم الاستفادة من الأوقاف

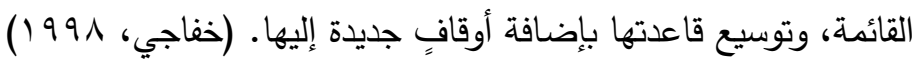

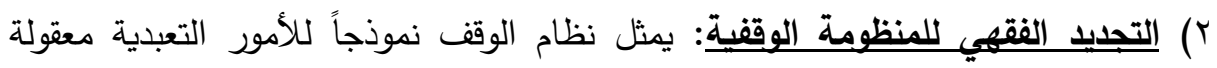

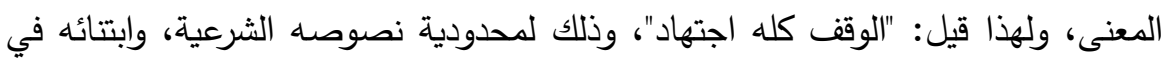
غالب قضاياه على الرؤية المقاصدية المصلحية، مما يفسح المجال لعلاج الجمود الفقهي لنظام الوقف عبر اجتهادات جديدة تتطرق إلى غالب جوانبه، فمن ذلك: اجتهاد مشروعية

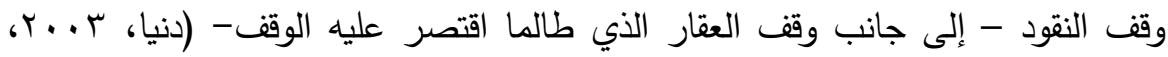

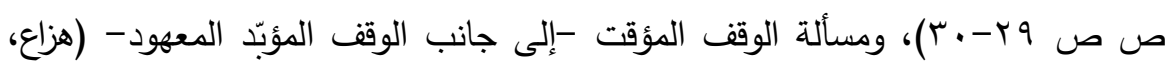

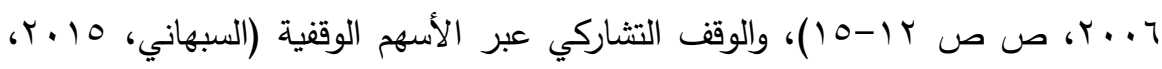

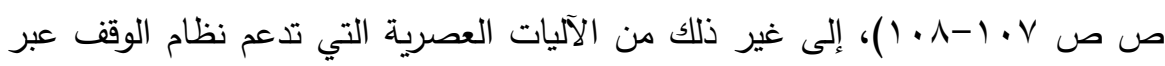

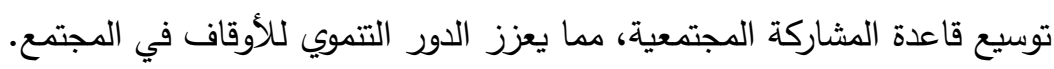

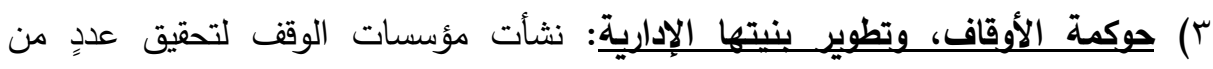
المقاصد، عبر مختلف الأنشطة والمشروعات الاجتماعية والاقتصادية، وفقاً لنظام قانوني لوني

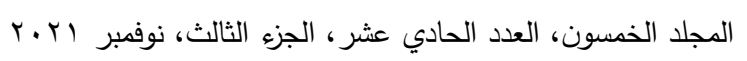

الترقيم الدولي 0826- ISSN 1110 الترقيم الدولي الموحد الإكتروني 3178-2636 
مستمد من الثريعة، وعبر آلياتٍ تتظيمية مرتبطة بواقع وظروف المجتمع، ومن ثّ تتأثر بمستجدات النظم الإدارية، والتي أفرزت في الواقع المعاصر كثيراً من التطورات التي تستلزم

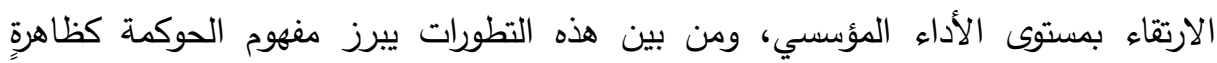
حديثة، يمكن أن تثري أداء النظام الوقفي، كمنصةٍ ضامنة لادهي لتحقيق مبادئ العدالة والثفافية والمساءلة، ويشير المفهوم إلى مجموعة المعايير والقواعد والإجراءات التي تجري بموجبها إدها إدارة

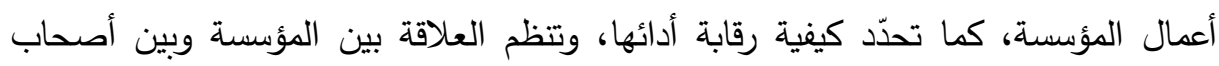

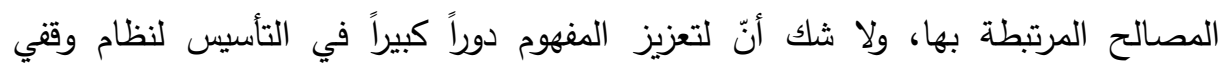
معاصر ، وتحسين قدرات مؤسسات الوقف وزيادة فعاليتها، وتحقيق العدالة والثفافية ومكافحة الفساد.

كما يستلزم التجديد المأمول تطوير البنية الإداري لمؤسسات الوقف، وبديلاً عن نموذج "ناظر الوقف" -كإدارة فردية للوقف-؛ يجب التوجّه نحو الإدارة المؤسسية والاحترافية

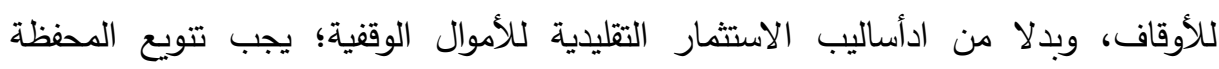
الاستثمارية للأوقاف بثكل احترافي -في ظل الضوابط الثرعية اللازمة-، لتحقيق أفضل عوائد ممكنة للأوقاف.

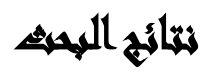

توصل البحث إلى عدد من النتائج، والتي يمكن عرضها من خلال النقاط التالية: العلاقة الإيجابية بين نظام الوقف وبين التنمية المستدامة:

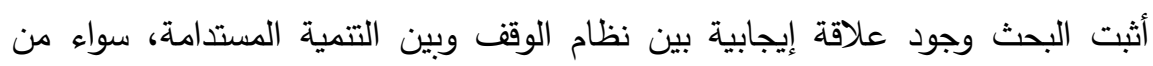

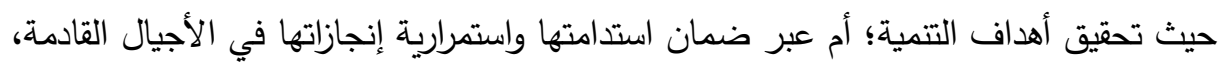
وتميزت الإنجازات التتموية للأوقاف بسمتين بارزتين، أولاها: حيث امتدت أهداف التتمية الوقفية لتثمل كافة الجوانب الروحية والاجتماعية والاقتصادية والعلمية و ل...إلخ، والأخرى:

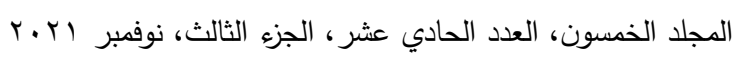

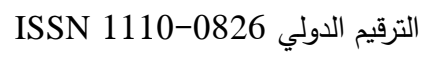

$$
\text { الترقيم الدولي الموحد الإكتروني 3178-2636 }
$$


سمة الاستدامة، حيث ضمنت أصول الوقف مورداً مالياً ثابتاً ومستمراً، يتمّ توجيهه لتمويل الخدمات الوقفية التي قررها الواقف، ونظراً لبقاء واستمرارية تلك الأصول الوقفية ومواردها المالية؛ فقد ضمنت تلك المشرعات التموية بذلك عنصر الاستدامة اللازم لاستمرارية أنشطتها.

إمكانية استئناف الدور التنموي للأوقاف في الواقع المصري:

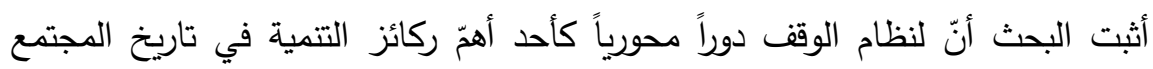
المصري، مما يثير إلى إمكانية استئناف الأوقاف لذلك الدور التاريخي في الواقع الراهن،

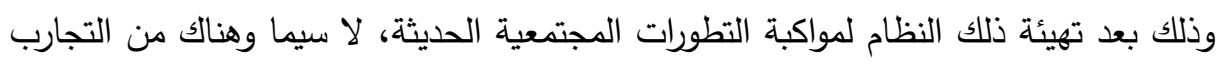
الرائدة في المجتمعات المسلمة والدول الغربية- ما يعزز هذه التوجهات ويؤكّد مصداقيتها. أهمية -بل ضرورة- تطوير الاراسات الوقفية:

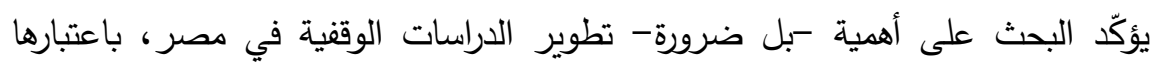
أساساً للإحياء الوقفي المأمول، حيث يؤدي تراكم هذه الدراسات إلى تسليط الضوه بلى على ألى أهمية نظام الوقف كأحد أهم الأسس اللازمة لتحقيق التتمية المستدامة، ولا سيما مع إبراز الدور التاريخي للأوقاف في أداء هذا الدور، وإضافةً إلى دورها في التوعية بالأهمية التنموية

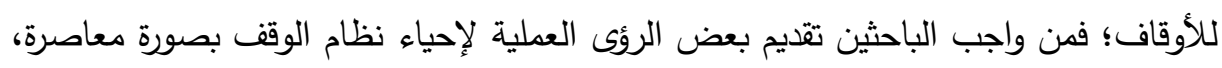

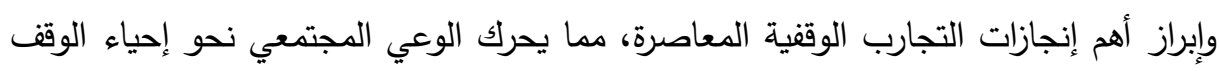

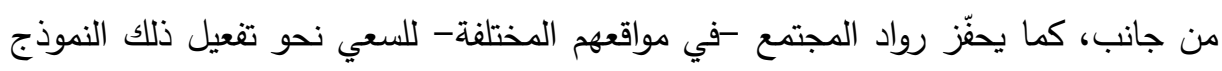
ليستأنف مسيرته التنموية في الواقع. يحز رواد الجتع

\section{التموصيامت}

بناء على ما تّّ استعراضه فإن البحث يوصي بما يلي: 1-تكثيف الدراسات الوقفية، والمتعلقة بثلاث جوانب:

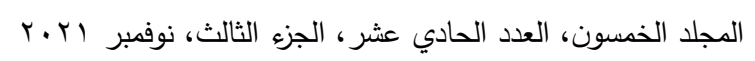

الترقيم الدولي الترقيم الدولي الموحد الإكتروني 3178-2636 
أولها: إبراز الإنجازات التاريخية لنظام الوقف، كنوع من الترويج والتوعية بمفهوم الوقف، سعياً

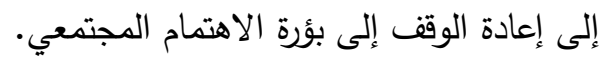
والثاني: عرض وتحليل تجارب الوقف الدولية -الإسلامية والغربية-، لاستلهام معاني الإحياء.

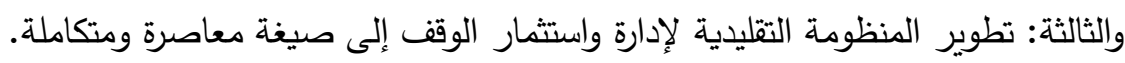
r- السعي إلى تقليص القبضة البيروقراطية على نظام الوقف ليستعيد حيويته عبر استقلالها.

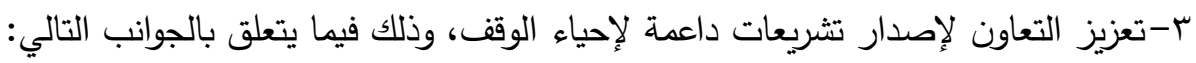

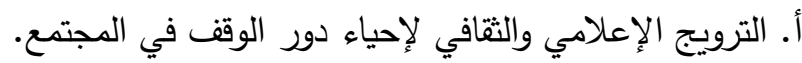
ب. الإدارة الأهلية -أو على الأقل المشتركة مع الحكومة- لنظام الوقفي.

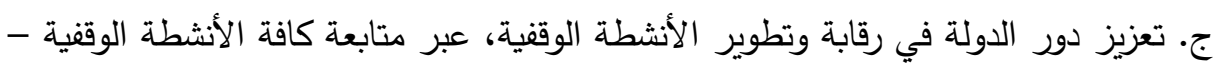

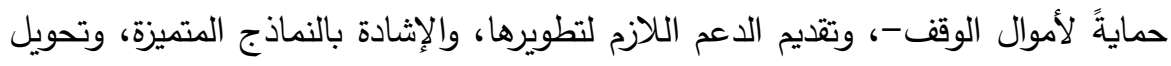

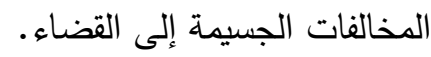

\section{المرالئ}

إبراهيم البيومي غانم (991()): الأوقاف والسياسة في مصر ، القاهرة : دار الثروق.

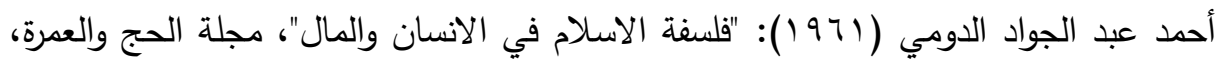

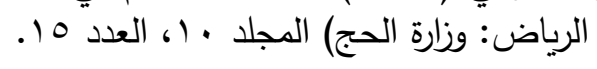

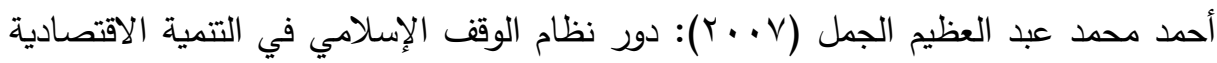
المعاصرة، القاهرة : دار السلام للطباعة والنشر والتوزيع والترجمة.

إسماعيل رسلان (£ (199): قواعد أساسية في البحث العلمي، مؤسسة الرسالة، بيروت.

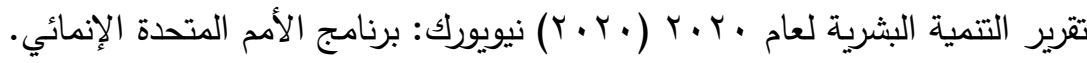

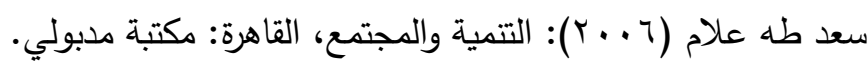

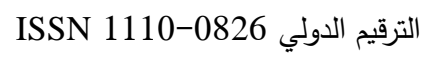
الترقيم الدولي الموحد الإكتروني 3178-2636 


$$
\begin{aligned}
& \text { مجلة العلوم البيئية } \\
& \text { كلية الدراسات العليا والبحوث البيئية - جامعة عين شمس لبئة البه } \\
& \text { محمد أحمد عبد اللطيف وآخرون }
\end{aligned}
$$

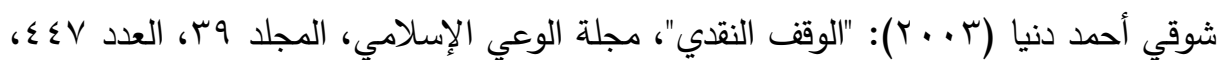

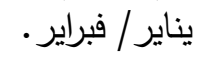

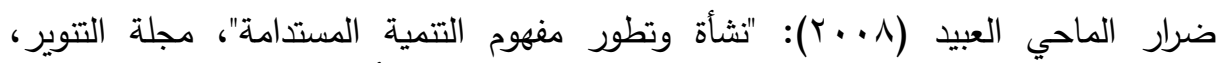
الخرطوم: مركز التتوير المعرفي، العدد الخامس، أبريل.

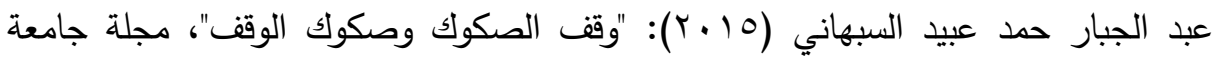

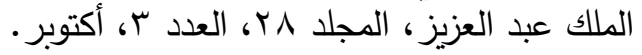

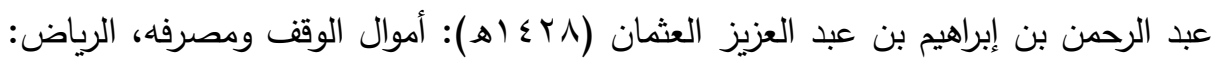
وكالة المطبوعات والبحث العلمي.

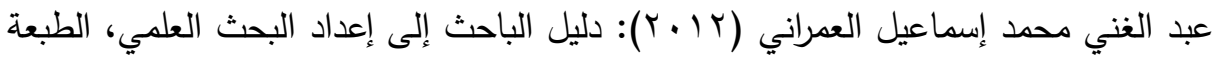
الثانية، صنعاء: دار الكتاب الجامعي.

عكرمة سعيد صبري (11 (r): الوقف الإسلامي بين النظرية والتطبيق، الطبعة الثانية، عمّان: دار النفائس للنشر والتوزيع. الإندي

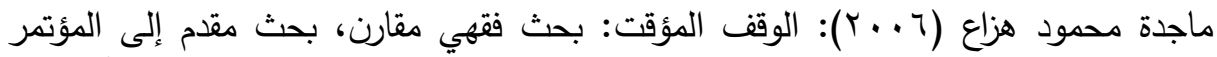

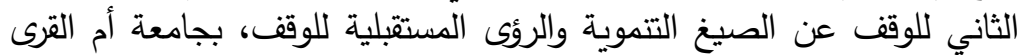

$$
\text { بمكة المكرمة. }
$$

محمد بن عبد العزيز بن عبد الله (997 1): الوقف في الفكر الإسلامي، الرباط: وزارة الأوقاف والثؤون الإسلامية.

محمد عبيد الكبيسي (9VVV) ( ) أحكام الوقف في الثريعة الإسلامية، بغداد: مطبعة الإرشاد.

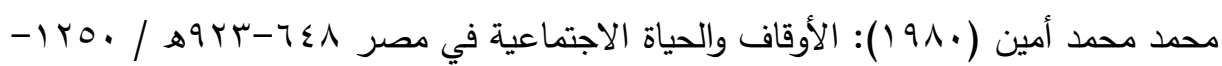

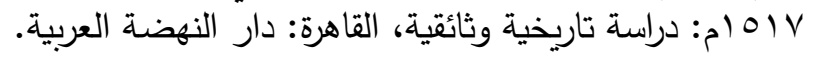

Abdullah, Adam and Saiti, Buerhan, (2016): "A Re-Examination of Musharakah Bonds and Waqf Development: The Case of Singapore", Intellectual Discourse, Special Issue.

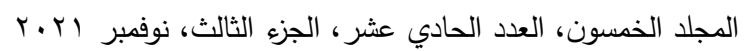

$$
\begin{aligned}
& \text { الترقيم الدولي 0826-0 التئ } \\
& \text { الترقيم الدولي الموحد الإلكتروني 3178-2636 }
\end{aligned}
$$




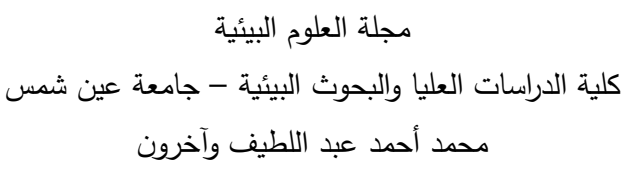

\title{
THE ROLE OF WAQF SYSTEM IN ACHIEVING DEVELOPMENT AND ENSURING ITS SUSTAINABILITY
}

\author{
Mohamed A. Abd El-Latif ${ }^{(1)}$; Abeer A. Farahat ${ }^{(2)}$ \\ and Yousry A. Saad Eddin ${ }^{(3)}$
}

1) Post graduate student at Faculty of Graduate Studies and Environmental Research, Ain Shams University 2) Faculty of Commerce, Ain Shams University 3) Faculty of Religion Fundamentals, Al-Azhar University

\begin{abstract}
The concept of development has been receiving a wide attention since the mid-twentieth century, as the hope of developing countries to overcome their crises and achieve the social welfare for their citizens. Despite the successive evolution of the developments concept development have followed, the conditions of the majority of developing countries have remained without remarkable achievement, which requires the creation of new developmental proposals interact with the identity of these societies, and stimulates community participation efforts to achieve the desired accumulation. Awqaf system is one of the pillars of this vision, as it has historically been able to achieve development goals and meet the needs of society. Its continuity system has represented an early model for sustainable development, despite its diminished role in modern reality. Since the eighties, many Muslim societies have witnessed a wave of thought calling for the revival of the endowment, and looking to resume its role after making the adjustments required by the changes in reality and its contemporary developments. This research seeks to contribute to these efforts, drawing inspiration from Awqaf historical roles, which motivates the 284

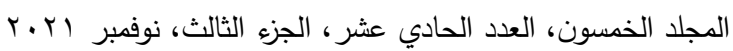

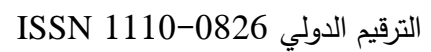

$$
\begin{aligned}
& \text { الترقيم الدولي الموحد الإلكتروني 3178-2636 }
\end{aligned}
$$




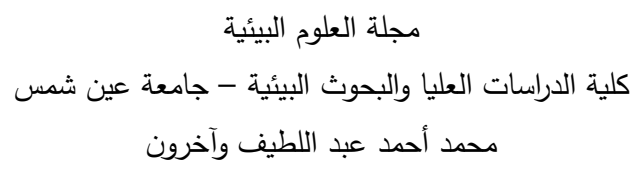

re-consideration of this system -with its comprehensiveness and independence- to the public sphere. For this reason, the research resorted to using the historical/ descriptive approach to understand and analuse the dimensions of the phenomenon and its rooting in the reality of society.

The research concluded with a number of results, the most important are: the necessity of continuing efforts to try to restore the endowment system from the government's hegemony to the civil sphere, while ensuring the continuation of the protective role of the state, in addition to other forms of support for the endowment system such as legislation and tax incentives.

The research also presented a set of recommendations, including: The importance of diligence to develop the endowment system from both sides: jurisprudence, through new innovations for the patterns and foundations of endowment, and administrative: by developing systems for Awqaf managing and investing, in a manner that reassures society towards the safety and feasibility of directing donations to this sector.

Key words: Endowment system - Awqaf/ Waqf system in Egypt Achievements of Awqaf - Revival of Awqaf - Awqaf problems.

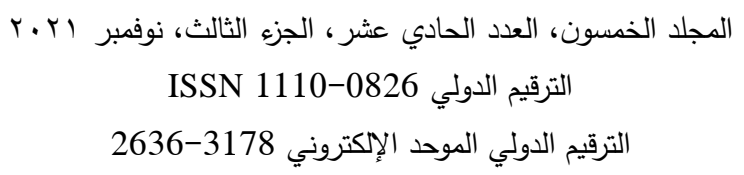

